\title{
Short communication: A splice site mutation in CENPU is associated with recessive embryonic lethality in Holstein cattle
}

\author{
C. Hozé, ${ }^{1,2}$ C. Escouflaire, ${ }^{1,2}$ M. Mesbah-Uddin, ${ }^{2,3} \odot$ A. Barbat, ${ }^{2}$ M. Boussaha, ${ }^{2}$ M. C. Deloche, ${ }^{1,2}$ D. Boichard, ${ }^{2} \odot$ \\ S. Fritz, ${ }^{1,2}$ and A. Capitan ${ }^{1,2 *}$ (D) \\ ${ }^{1}$ Allice, 75595 Paris, France \\ ${ }^{2} \mathrm{GABI}$, INRA, AgroParisTech, Université Paris-Saclay, 78350 Jouy-en-Josas, France \\ ${ }^{3}$ Department of Molecular Biology and Genetics, Center for Quantitative Genetics and Genomics, Aarhus University, 8830 Tjele, Denmark
}

\section{ABSTRACT}

A genome scan for homozygous haplotype deficiency coupled with whole-genome sequence data analysis is a very effective method to identify embryonic lethal mutations in cattle. Among other factors, the power of the approach depends on the availability of a greater amount of genotyping and sequencing data. In the present study, we analyzed the largest known panel of Illumina BovineSNP50 (Illumina Inc., San Diego, CA) genotypes, comprising 401,896 Holstein animals, and we report the mapping of a new embryonic lethal haplotype on chromosome 27, called HH7. We fine mapped the locus in a $2.0-\mathrm{Mb}$ interval using an identical-bydescent approach and analyzed genome sequence data from 4 carrier and 143 noncarrier Holstein bulls to identify the causative mutation. We detected a strong candidate variant in the gene encoding centromere protein $\mathrm{U}(C E N P U)$, a centromere component essential for proper chromosome segregation during mitosis. The mutant allele is a deletion of 4 nucleotides located at position +3 to +6 bp after the splicing donor site of exon 11. Cross-species nucleotide alignment revealed that the nucleotide at position +3 is entirely conserved among vertebrates, suggesting that it plays an important role in the regulation of CENPU splicing. For verification, we genotyped the candidate variant in 232,775 Holstein individuals and did not observe any homozygotes, whereas 16 were expected (Poisson $P$-value $=1.1 \times 10^{-7} ;$ allele frequency $\left.=0.8 \%\right)$. In addition, genotyping of 250,602 animals from 19 additional breeds revealed that the mutant allele is restricted to animals of Holstein descent. Finally, we estimated the effect of the candidate variant on 2 fertility traits in at-risk mating (i.e., between carrier bulls and daughters of carrier bulls) versus non-risk mating. In agreement

Received June 3, 2019.

Accepted September 2, 2019.

*Corresponding author: aurelien.capitan@inra.fr with a recessive lethal inheritance pattern, we observed a marked reduction in both conception rate and 56-d nonreturn rate in heifers and cows. The effect on 56-d nonreturn rate suggests that a substantial proportion of homozygous mutants die before $35 \mathrm{~d}$ after insemination, which is consistent with the early embryonic death previously reported in $\mathrm{CENPU}^{-/}$mouse embryos. In conclusion, we demonstrate that with more than 400,000 genotypes, we can map very rare recessive lethal mutations segregating at a frequency below $1 \%$ in the population. We recommend performing new analyses regularly as data are accumulating.

Key words: embryonic lethal, $C E N P U$, homozygous haplotype deficiency, Holstein, large-scale genotyping

\section{Short Communication}

Detecting depletions in homozygotes for specific haplotypes among large cohorts of animals genotyped for genomic selection is a particularly effective method for mapping recessive mutations causing embryonic lethality (VanRaden et al., 2011; Fritz et al., 2013). This approach, supplemented by follow-up analyses, has led to the identification of 5 such mutations in the sole Holstein breed (HH1, HH3, HH4, HH5, and HH6; Fritz et al., 2013, 2018; Daetwyler et al., 2014; McClure et al., 2014; Adams et al., 2016; Schütz et al., 2016). Yet the power of the method depends on several parameters, of which the 3 most important are (1) the number of animals genotyped, (2) the frequency of the mutation within that population, and (3) the linkage disequilibrium between the haplotype and the mutation (Fritz et al., 2018). Linkage disequilibrium depends on mutation history and haplotype informativity. In dairy populations, these mutations are usually disseminated by recent popular bulls and are surrounded by large chromosomal segments of $\geq 1 \mathrm{Mb}$. Therefore, using medium-density SNP chips (containing $50 \mathrm{k}$ or $80 \mathrm{k}$ markers) provides enough haplotype variability to ensure high linkage disequilibrium and a reduced number 
of false-positive or false-negative results. Obviously, older mutations surrounded by a shorter ancestral segment would require higher marker density for detection. Generally, cohorts of 2,000 animals are sufficient to detect lethal haplotypes with a frequency of $10 \%$, and more than 200,000 animals are necessary to obtain significant results for haplotypes with a frequency of $1 \%$. Therefore, it is expected that the regular increase in genotyping databases will lead to regular identification of new deleterious haplotypes segregating at low frequencies in the populations analyzed.

In this context, we performed a new analysis on the most recent data available with methods we developed in previous studies (Michot et al., 2017; Fritz et al., 2018; Mesbah-Uddin et al., 2019).

The total data set comprised real or imputed phased Illumina BovineSNP50 (Illumina Inc., San Diego, CA) genotypes from 401,896 French Holstein animals with sire and dam $(\mathrm{n}=160,710)$ or sire and maternal grandsire genotyped $(\mathrm{n}=241,186)$. Genotypes obtained with different Illumina SNP chips (BovineSNP50 BeadChip v1 and v2, Matukumalli et al., 2009; LD chip, Boichard et al., 2012a; BovineHD chip and EuroG10K, Boichard et al., 2018) were processed using the French genomic selection pipeline (for details, see Boichard et al., 2012b and Hozé et al., 2013), and phased and imputed using FImpute version 2.2 (Sargolzaei et al., 2014). After quality control, phased genotype data for 43,801 markers were analyzed using sliding windows of 20 markers (i.e., approximately $1.5 \mathrm{Mb}$ ). The population frequency of each haplotype was calculated from the maternal autosomal phases, and 699,028 haplotypes with a frequency $>1 \%$ were considered thereafter. The number of observed homozygous progeny, $\operatorname{Nobs}(k)$, was counted for each haplotype $k$ and compared with its expectation, $\operatorname{Nexp}(k)$, under the null hypothesis of neutrality. The value of $N \exp (k)$ was either directly estimated from the genotypes of the parents or from the genotypes of the sire and maternal grandsire and the frequency in the population, as described in Fritz et al. (2013). The probability of observing " $q$ " homozygotes with expectation of "lambda" was calculated using the Poisson distribution "ppois( $q$, lambda)" function in R software version 3.4.3 (R Core Team, 2017). A Bonferroni correction, consisting of multiplying the $P$-values obtained by the number of haplotypes tested, was applied to account for multiple testing, and neighbor windows with the same minimum number of homozygous products were merged to define intervals. Finally, a recessive defect causing embryonic or early postnatal lethality was suspected when the Bonferroni-adjusted Poisson $P$-value was $<0.05$ and the $N \operatorname{obs}(k) / N \exp (k)$ ratio was $<0.25$.

In doing so, we identified 7 target regions (Table 1). Six corresponded to known recessive mutations causing embryonic lethality (HH1, HH3, HH4, HH5, and HH6) or both embryonic lethality and stillbirth (HBY: brachyspina; Charlier et al., 2012). In addition, we identified a new haplotype, called $\mathrm{HH}$, consisting of 30 consecutive markers on chromosome 27 (from BTA63422-no-rs at positions $12,982,268$ bp to ARS-BFGLNGS-3694 at position 14,292,852 bp on the bovine genome assembly UMD3.1; Zimin et al., 2009) with 0 homozygotes observed for 18 expected (Bonferroniadjusted Poisson $P$-value $=1.1 \times 10^{-02} ;$ haplotype frequency $=1.1 \%$ ).

By analyzing pedigree and haplotype information, we found that HH7 has been disseminated in French Holsteins through 3 main sources over the last $50 \mathrm{yr}$ : SECRET (HOLUSAM000001856904, born in 1980), MERDRIGNAC (HOLFRAM002296001756, born in 1996), and DUTCH BOY (HOLUSAM000017058140, born in 1996), who have limited genetic contributions to the present day population (estimated at 1.0, 0.4, and $1.2 \%$, respectively, for animals born between 2014 and 2018, using the pedig package; Boichard, 2002). SECRET and MERDRIGNAC share a common segment of $6.9 \mathrm{Mb}$ on chromosome 27 (147 markers from positions

Table 1. List of regions displaying significant depletions in homozygotes ${ }^{1}$

\begin{tabular}{llccccc}
\hline Haplotype $^{2}$ & BTA & $\begin{array}{c}\text { Interval } \\
(\mathrm{Mb})\end{array}$ & $\begin{array}{c}\text { Frequency } \\
(\%)\end{array}$ & Nexp & Nobs & $\begin{array}{c}\text { Bonferroni-adjusted } \\
\text { Poisson P-value }\end{array}$ \\
\hline HH3 & 8 & $94.5-95.6$ & 3.1 & 389 & 0 & $8.0 \times 10^{-164}$ \\
HH4 & 1 & $0.1-1.3$ & 4.2 & 377 & 5 & $8.4 \times 10^{-148}$ \\
HH5 & 9 & $92.4-93.2$ & 1.8 & 149 & 4 & $2.9 \times 10^{-52}$ \\
HBY & 21 & $20.0-21.2$ & 2.4 & 116 & 1 & $3.4 \times 10^{-43}$ \\
HH1 & 5 & $62.7-64.4$ & 1.6 & 56 & 0 & $3.3 \times 10^{-19}$ \\
HH6 & 16 & $31.1-31.9$ & 1.6 & 59 & 5 & $1.1 \times 10^{-13}$ \\
HH7 & 27 & $13.0-14.3$ & 1.1 & 18 & 0 & $1.1 \times 10^{-02}$ \\
\hline
\end{tabular}

${ }^{1}$ Nexp = number of homozygotes expected; Nobs = number of homozygotes observed. Only regions with a Bonferroni adjusted Poisson $P$-value $<0.05$ and a Nobs: Nexp ratio $<25 \%$ are displayed.

${ }^{2} \mathrm{HH} 1, \mathrm{HH} 3, \mathrm{HH} 4, \mathrm{HH} 5, \mathrm{HH}$, and $\mathrm{HH} 7$ correspond to known recessive mutations causing embryonic lethality; HBY causes both embryonic lethality and stillbirth. 
$10,764,825$ to $17,676,145 \mathrm{bp})$. This segment was traced back in the pedigree of MERDRIGNAC to its greatgreat grandsire STEADY (HOLUSAM000001829401, born in 1979) and to the grandsire of the latter, GAY (HOLUSAM000001512026, born in 1967). Importantly, GAY and SECRET are, respectively, grandson and greatgrandson of IVANHOE SH (HOLUSAM000001189870, born in 1956), who might be one of the oldest sources of the HH7 haplotype. In contrast, DUTCH BOY shares only a small 1.9-Mb segment with GAY and SECRET (44 markers from positions $12,982,268$ to $14,901,236$ $\mathrm{bp})$. Analyzing the pedigree of DUTCH BOY, we found one occurrence of IVANHOE SH, 7 generations ago, via BLACKSTAR (HOLUSAM000001929410, born in 1983). However, haplotype data revealed that BLACKSTAR did not carry HH7. The lack of pedigree information for animals born before the 1950s and the lack of genotypes before the 1970s did not enable us to identify a common ancestor of SECRET, MERDRIGNAC (or GAY), and DUTCH BOY who transmitted the HH7 haplotype. We conclude that HH7 segregates at a low frequency $(1.1 \%)$ and has been introduced several times in the French Holstein breed. This situation is unusual because previously published lethal haplotypes generally segregate at higher frequencies and are massively diffused by popular elite sires (e.g., the frequency of $\mathrm{HH} 4$ increased from close to 0 to $4.2 \%$ in less than $20 \mathrm{yr}$ with the massive use of JOCKO BESNE; HOLFRAM005694028588, born in 1994, and his descendants).

This situation represents a double-edged sword. First, the existence of ancient recombination events is an advantage for fine mapping the lethal mutation associated with HH7. However, there is a risk that 2 versions of the haplotype segregates in the population (an ancestral version, predating the mutation event, and a second with the lethal mutation), which would bias the results.

For verification, we considered a region of 64 markers (between positions 12,523,146 and 15,291371 bp) and differentiated the $\mathrm{HH} 7$ segments originating from SECRET or MERDRIGNAC from those derived from DUTCH BOY. This region corresponded to the 44 markers shared by the 3 bulls plus 10 additional markers on each side. We estimated that, out of the 18 homozygous expected for HH7, 10 would carry one copy inherited from SECRET or MERDRIGNAC and a second copy from DUTCH BOY; zero were observed (Poisson $P$-value $=4.5 \times 10^{-5}$ for 0 vs. 10 expected) . Therefore, we assumed that the 3 bulls carry the same lethal mutation in a mapping interval defined by the most proximal markers outside of the 44-marker identical-by-descent segment (i.e., between positions $12,930,436$ bp and 14,931,898 bp on chromosome 27).
We then examined several Holstein genomes sequenced with Illumina technology (Supplemental Table S1a; https://doi.org/10.3168/jds.2018-17056) to detect SNPs and small insertions and deletions $(\mathrm{n}=4$ carriers, including DUTCH BOY and MERDRIGNAC, and 143 noncarriers available from run 4 of the 1000 Bull Genomes Consortium; Daetwyler et al., 2014), as well as structural variations $(\mathrm{n}=3$ carriers and 44 noncarriers analyzed as described in Boussaha et al., 2015). After calculating Pearson correlations between haplotype status and allele dosages for biallelic variants, we identified 15 perfectly correlated variants $(\mathrm{r}=$ 1) within the refined mapping interval (Supplemental Table S1b). All were located in noncoding parts of the genome according to Variant Effect Predictor (VEP v87; McLaren et al., 2016). Using cross-species conservation analysis (Genomic Evolutionary Rate Profiling score, www.ensembl.org), we highlighted a 4-bp deletion (Chr27 g.14168130_14168133delTACT) that affects a highly conserved region among mammals. More precisely, this variant consists of a deletion of 1 of the 2 copies of a short tandem repeat located at the end of exon 11 and the beginning of intron 11 of a strong functional candidate gene, $C E N P U$, which encodes the centromere protein U (CENPU, also known as MLF1interacting protein), a centromere component essential for proper chromosome segregation during mitosis. As a consequence, the suppression of CENPU in human HeLa cells by short hairpin (sh)RNA causes mitotic defects with an impaired kinetochore-microtubule attachment (Hua et al., 2011). Mice homozygous for a knockout allele exhibit embryonic lethality between somite formation and embryo turning (Wang et al., 2013). Considering that CENPU is transcribed in the antisense orientation, this mutation is predicted to result in deletion of the nucleotides located at position +3 to +6 bp after the splicing donor site of exon 11 . Using cross-species nucleotide alignment, we observed that the nucleotide at position +3 is entirely conserved among vertebrates (Figure 1), which suggests that it plays an important role in regulation of $C E N P U$ splicing. If modified after exon 11, the abnormal splicing of CENPU could cause mRNA decay or the production of a protein modified after residue 319 out of 409 AA. Based on these factors, we assumed that mutation g.14168130_14168133delTACT on chromosome 27 alters the splicing of CENPU and is embryonic lethal.

Interestingly, in the framework of a reverse genetics study (A. Capitan, unpublished data, 2013), a probe had been designed to genotype this variant on the Illumina EuroG10K SNP chip (with the following source sequence: ACGTGAAATGCTGCGATTAAATCCCTATTTTAAGTTCTCAAAGAGAATTTCGATATTACT[T/G]NNAAGCAGTTCATCCTG- 
GACTTCAATCAAACGCTGCCTTTTCTTTTCGATATTGGAGATT). Briefly, the latter project consisted of (1) identifying putative deleterious mutations found in run 4 of the 1000 Bull Genome Consortium (Daetwyler et al., 2014), following an approach similar to those of Michot et al. (2016) and Charlier et al. (2016); and (2) designing probes on the Illumina EuroG10K SNP chip for 500 recessive variants predicted to have dramatic phenotypic consequences.
Genotypes for the CENPU mutation were available from the French genotypes database for a total of 232,775 Holstein and 250,602 animals from 19 additional breeds (Supplemental Table S2; https://doi .org/10.3168/jds.2019-17056). In agreement with our hypothesis, no homozygotes for the deletion were observed, whereas 16 were expected in Holsteins (Poisson $P$-value $=1.1 \times 10^{-7}$, allele frequency $\left.=0.8 \%\right)$. No carrier of the mutation was observed in other breeds, with

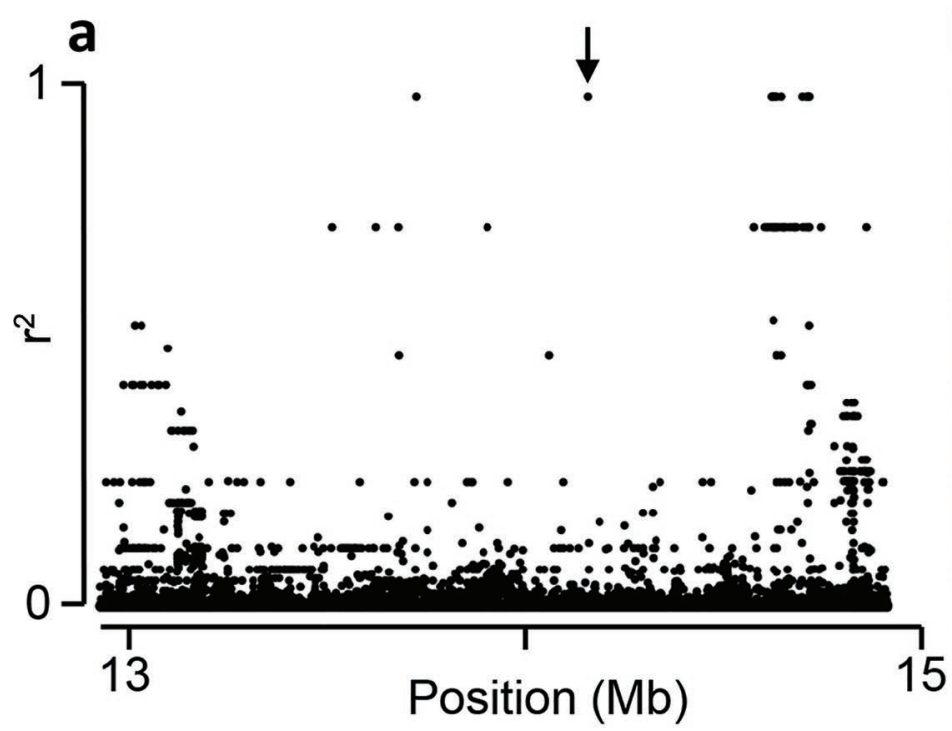

b

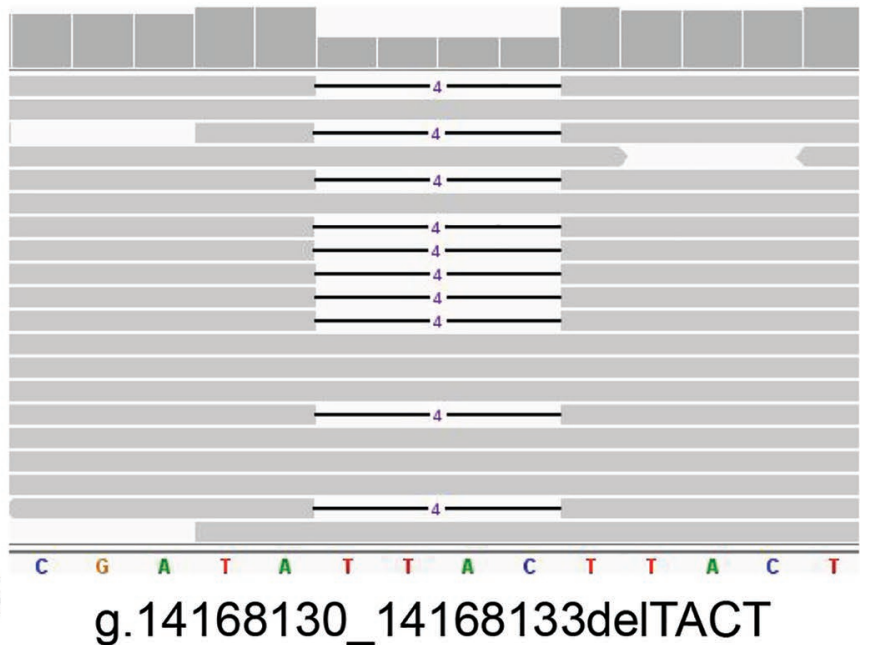

C

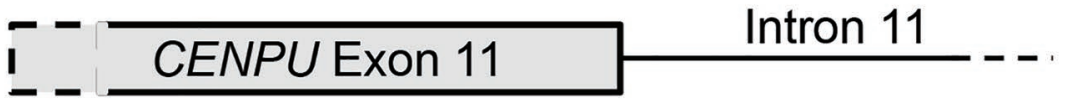

Cow mutant

TGAAGTCCAGGATGAACTGCTTCAGTAATATCGAAATTCTCTTT

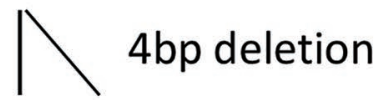

$\begin{array}{ll}\text { Mammal } & \text { Cow } \\ \text { Mammal } & \text { Mouse } \\ \text { Mammal } & \text { Human } \\ \text { Reptile } & \text { Anole Lizard } \\ \text { Amphibian } & \text { Xenopus } \\ \text { Bird } & \text { Chicken } \\ \text { Fish } & \text { Spotted Gar }\end{array}$

TGAAGTCCAGGATGAACTGCTTCAGTAAGTAATATCGAAATTCT TGAAGTCCAGGATGAACTGATTCGGTAAGGTAATATCTGCTCTA TGAAGTCCAGGATGAACTGCTTCGGTAAGATACTGTCAAATCCT AGACGTTAAAGAAGAAGTAATTAAGTATGTTCTCAATGGTTAAA TAGCAGGAGAGAGGAACTAATTGAGTAAGTTATATCTTATAATT GCAAGTCAGAGAAAAGCTAAGTAGGTACGTCTCCAATAGTGCAC GGAGGTCAAACACGAACTAAGGAAGTAAGTAGAGTTTGCGCACC

Figure 1. Identification of a putative causal variant within the HH7 locus. (a) Squared Pearson correlation $\left(\mathrm{r}^{2}\right)$ between haplotype status and allele dosage of whole-genome sequencing (WGS) variants. Each dot in the scatterplot indicates a WGS variant, and variant g.14168130_14168133delTACT is indicated by an arrow. The list of variants with $\mathrm{r}^{2}=1$ is provided in Supplemental Table S1b (https://doi .org/10.3168/jds.2019-17056). (b) Integrative Genomic Viewer (IGV; https://software.broadinstitute.org/software/igv/) screenshot showing the 4-bp deletion in the genome of the heterozygous carrier bull MERDRIGNAC. (c) Multi-species sequence alignment of 47 nucleotides at the junction of exon 11 and intron 11 of $C E N P U$ in 7 vertebrate species, using CLUSTALW (https://www.genome.jp/tools-bin/clustalw). Note that the sequences are provided in the antisense orientation relative to the bovine UMD3.1 genome assembly. An asterisk $(*)$ at the bottom of the alignment represents nucleotides conserved in all the species. 
Table 2. Estimated effect of CENPU variant g.14168130_14168133delTACT on conception rate (CR) and 56-d nonreturn rate (NRR56) in at-risk mating

\begin{tabular}{|c|c|c|c|c|c|c|}
\hline \multirow[b]{2}{*}{ Trait } & \multirow[b]{2}{*}{ Category } & \multicolumn{2}{|c|}{ Number of matings } & \multicolumn{3}{|c|}{ Effect on fertility (\%) } \\
\hline & & Non-risk & At-risk & Expected $^{1}$ & Observed & $\begin{array}{l}\text { Observed/ } \\
\text { expected }\end{array}$ \\
\hline \multirow[t]{2}{*}{$\mathrm{CR}$} & Heifer & $12,639,553$ & 5,322 & -7.28 & -7.38 & 1.01 \\
\hline & Cow & $31,350,847$ & 22,659 & -4.96 & -3.33 & 0.67 \\
\hline \multirow{2}{*}{ NRR56 } & Heifer & $7,760,950$ & 2,961 & -9.31 & -4.99 & 0.54 \\
\hline & Cow & $15,819,082$ & 11,360 & -7.72 & -3.46 & 0.45 \\
\hline
\end{tabular}

${ }^{1}$ Expected effects on CR and NRR56 were calculated using the formula: $\frac{1}{4}\left(\frac{1}{2-f_{h a p_{-} k}}\right) \mu$; where $f_{\text {hap } \_k}$ is the

frequency of the mutant allele in the population, and $\mu$ is the phenotypic mean of CR or NRR56; $\mu$ was equal to $58.03,39.53,74.15$, and $61.53 \%$ for CR in heifer, CR in cow, NRR56 in heifer, and NRR56 in cow, respectively.

the exception of one Montbéliarde cow that was found to have Holstein ancestry (Supplemental Table S2).

To further evaluate its impact, we estimated the effect of variant g.14168130_14168133delTACT on 2 fertility traits in at-risk mating (i.e., between carrier bulls and daughters of carrier bulls) versus non-risk mating. Conception rate $(\mathbf{C R})$ is the percentage of cows that give birth to a calf after a normal gestation length (282 $\mathrm{d} \pm 19 \mathrm{~d})$ out of the total number of cows inseminated, whereas 56-d nonreturn rate (NRR56) is the proportion of cows that are not subsequently inseminated within $56 \mathrm{~d}$ after an insemination. Considering that the ovarian cycle averages $21 \mathrm{~d}$ in cattle, NRR56 measures the proportion of cows that are assumed to be pregnant at $35 \mathrm{~d}$ of gestation. We observed a marked reduction in both NRR56 and CR in heifers and cows in at-risk mating (Table 2), which is consistent with a recessive lethal inheritance. For NRR56, the ratio "effect on fertility observed: effect on fertility expected" was 0.54 and 0.45 for heifers and cows, respectively, suggesting that about half of the homozygous mutants die before $35 \mathrm{~d}$ of insemination. This observation is compatible with a death between somitogenesis (i.e., around 18 and $21 \mathrm{~d}$ of gestation in cattle; Barone, 2001) and embryo turning (at d 25 in cattle; Barone, 2001), as observed in CENPU $^{-1-}$ mouse embryos (Wang et al., 2013).

In conclusion, we report a new embryonic lethal haplotype in Holstein cattle and a strong candidate variant in $C E N P U$, segregating at a frequency of $0.8 \%$ in the French Holstein cattle population. Our study reconfirms the power of genome scans for homozygous haplotype deficiency with large data sets of SNP chip genotypes, analyses of whole-genome sequencing, and large-scale genotyping of candidate variants. As data accumulate, we recommend performing new analyses on a regular basis to detect even rarer embryonic lethal mutations. The low frequency of these mutations should facilitate their management by avoiding at-risk mating and pro- gressively reducing the proportion of carriers among AI bulls.

\section{ACKNOWLEDGMENTS}

This study is part of the BOVANO project (ANR-14CE19-0011) funded by the French Agence Nationale de la Recherche (Paris, France) and APIS-GENE (Paris, France). The authors are grateful to the partners of the 1000 bull genomes consortium for their excellent collaboration.

\section{REFERENCES}

Adams, H. A., T. S. Sonstegard, P. M. VanRaden, D. J. Null, C. P. Van Tassell, D. M. Larkin, and H. A. Lewin. 2016. Identification of a nonsense mutation in APAF1 that is likely causal for a decrease in reproductive efficiency in Holstein dairy cattle. J. Dairy Sci. 99:6693-6701. https://doi.org/10.3168/jds.2015-10517.

Barone, R. 2001. Embryogenèse et formation des annexes. Pages 471493 in Anatomie Comparée des Mammifères Domestiques. Vol. 4. Ed. Vigot, Paris, France.

Boichard, D. 2002. PEDIG: A Fortran package for pedigree analysis suited for large populations. Page 28 in Proc. 7th World Congr Genet. Appl. Livest. Prod., Montpellier, France. INRA, CastanetTolosan, France.

Boichard, D., M. Boussaha, A. Capitan, D. Rocha, C. Hozé, M. P. Sanchez, T. Tribout, R. Letaief, P. Croiseau, C. Grohs, W. Li, C. Harland, C. Charlier, M. S. Lund, G. Sahana, M. Georges, S. Barbier, W. Coppieters, S. Fritz, and B. Guldbrandtsen. 2018. Experience from large scale use of the EuroGenomics custom SNP chip in cattle. Page 675 in Proc. World Congr. Genet. Appl. Livest. Prod., Auckland, New Zealand. AL Rae Centre for Genetics and Breeding, Massey University, Palmerston North, New Zealand. http:/ /www.wcgalp.org/system/files/proceedings/2018/experience-large -scale-use-eurogenomics-custom-snp-chip-cattle.pdf.

Boichard, D., H. Chung, R. Dassonneville, X. David, A. Eggen, S. Fritz, K. J. Gietzen, B. J. Hayes, C. T. Lawley, T. S. Sonstegard, C. P. Van Tassell, P. M. VanRaden, K. A. Viaud-Martinez, G. R. Wiggans, and L. D. C. Bovine. 2012a. Design of a bovine lowdensity SNP array optimized for imputation. PLoS One 7:e34130. https://doi.org/10.1371/journal.pone.0034130.

Boichard, D., F. Guillaume, A. Baur, P. Croiseau, M. N. Rossignol, M. Y. Boscher, T. Druet, L. Genestout, J. J. Colleau, L. Journaux, V. Ducrocq, and S. Fritz. 2012b. Genomic selection in French dairy 
cattle. Anim. Prod. Sci. 52:115-120. https://doi.org/10.1071/ AN11119.

Boussaha, M., D. Esquerre, J. Barbieri, A. Djari, A. Pinton, R. Letaief, G. Salin, F. Escudie, A. Roulet, S. Fritz, F. Samson, C. Grohs, M. Bernard, C. Klopp, D. Boichard, and D. Rocha. 2015. Genomewide study of structural variants in bovine Holstein, Montbeliarde and Normande dairy breeds. PLoS One 10:e0135931. https://doi .org/10.1371/journal.pone.0135931.

Charlier, C., J. S. Agerholm, W. Coppieters, P. Karlskov-Mortensen, W. Li, G. de Jong, C. Fasquelle, L. Karim, S. Cirera, N. Cambisano, N. Ahariz, E. Mullaart, M. Georges, and M. Fredholm. 2012. A deletion in the bovine FANCI gene compromises fertility by causing fetal death and brachyspina. PLoS One 7:e43085. https:// doi.org/10.1371/journal.pone.0043085.

Charlier, C., W. Li, C. Harland, M. Littlejohn, W. Coppieters, F. Creagh, S. Davis, T. Druet, P. Faux, F. Guillaume, L. Karim, M. Keehan, N. K. Kadri, N. Tamma, R. Spelman, and M. Georges. 2016. NGS-based reverse genetic screen for common embryonic lethal mutations compromising fertility in livestock. Genome Res. 26:1333-1341. https://doi.org/10.1101/gr.207076.116.

Daetwyler, H. D., A. Capitan, H. Pausch, P. Stothard, R. van Binsbergen, R. F. Brondum, X. Liao, A. Djari, S. C. Rodriguez, C. Grohs, D. Esquerre, O. Bouchez, M. N. Rossignol, C. Klopp, D. Rocha, S. Fritz, A. Eggen, P. J. Bowman, D. Coote, A. J. Chamberlain, C. Anderson, C. P. VanTassell, I. Hulsegge, M. E. Goddard, B. Guldbrandtsen, M. S. Lund, R. F. Veerkamp, D. A. Boichard, R. Fries, and B. J. Hayes. 2014. Whole-genome sequencing of 234 bulls facilitates mapping of monogenic and complex traits in cattle. Nat. Genet. 46:858-865. https://doi.org/10.1038/ng.3034.

Fritz, S., A. Capitan, A. Djari, S. C. Rodriguez, A. Barbat, A. Baur, C. Grohs, B. Weiss, M. Boussaha, D. Esquerre, C. Klopp, D. Rocha, and D. Boichard. 2013. Detection of haplotypes associated with prenatal death in dairy cattle and identification of deleterious mutations in GART, SHBG and SLC37A2. PLoS One 8:e65550. https://doi.org/10.1371/journal.pone.0065550.

Fritz, S., C. Hoze, E. Rebours, A. Barbat, M. Bizard, A. Chamberlain, C. Escouflaire, C. Vander Jagt, M. Boussaha, C. Grohs, A. Allais-Bonnet, M. Philippe, A. Vallee, Y. Amigues, B. J. Hayes, D. Boichard, and A. Capitan. 2018. An initiator codon mutation in SDE2 causes recessive embryonic lethality in Holstein cattle. J. Dairy Sci. 101:6220-6231. https://doi.org/10.3168/jds.2017-14119.

Hozé, C., M. N. Fouilloux, E. Venot, F. Guillaume, R. Dassonneville, S. Fritz, V. Ducrocq, F. Phocas, D. Boichard, and P. Croiseau. 2013. High-density marker imputation accuracy in sixteen French cattle breeds. Genet. Sel. Evol. 45:33. https://doi.org/10.1186/ 1297-9686-45-33.

Hua, S., Z. Wang, K. Jiang, Y. Huang, T. Ward, L. Zhao, Z. Dou, and X. Yao. 2011. CENP-U cooperates with Hec1 to orchestrate kinetochore-microtubule attachment. J. Biol. Chem. 286:1627-1638. https://doi.org/10.1074/jbc.M110.174946.

Matukumalli, L. K., C. T. Lawley, R. D. Schnabel, J. F. Taylor, M. F. Allan, M. P. Heaton, J. O'Connell, S. S. Moore, T. P. Smith, T. S. Sonstegard, and C. P. Van Tassell. 2009. Development and characterization of a high density SNP genotyping assay for cattle. PLoS One 4:e5350. https://doi.org/10.1371/journal.pone.0005350.

McClure, M. C., D. Bickhart, D. Null, P. Vanraden, L. Xu, G. Wiggans, G. Liu, S. Schroeder, J. Glasscock, J. Armstrong, J. B. Cole, C. P. Van Tassell, and T. S. Sonstegard. 2014. Bovine exome sequence analysis and targeted SNP genotyping of recessive fertility defects $\mathrm{BH} 1, \mathrm{HH} 2$, and $\mathrm{HH} 3$ reveal a putative causative mutation in SMC2 for HH3. PLoS One 9:e92769. https://doi.org/10.1371/ journal.pone.0092769.
McLaren, W., L. Gil, S. E. Hunt, H. S. Riat, G. R. Ritchie, A. Thormann, P. Flicek, and F. Cunningham. 2016. The Ensembl Variant Effect Predictor. Genome Biol. 17:122. https://doi.org/10.1186/ s13059-016-0974-4.

Mesbah-Uddin, M., C. Hozé, P. Michot, A. Barbat, R. Lefebvre, M. Boussaha, G. Sahana, S. Fritz, D. Boichard, and A. Capitan. 2019 A missense mutation (p.Tyr452Cys) in the CAD gene compromises reproductive success in French Normande cattle. J. Dairy Sci. 102:6340-6356. https://doi.org/10.3168/jds.2018-16100.

Michot, P., S. Chahory, A. Marete, C. Grohs, D. Dagios, E. Donzel, A. Boukadiri, M. C. Deloche, A. Allais-Bonnet, M. Chambrial, S. Barbey, L. Genestout, M. Boussaha, C. Danchin-Burge, S. Fritz, D. Boichard, and A. Capitan. 2016. A reverse genetic approach identifies an ancestral frameshift mutation in RP1 causing recessive progressive retinal degeneration in European cattle breeds. Genet. Sel. Evol. 48:56. https://doi.org/10.1186/s12711-016-0232 $-\mathrm{y}$.

Michot, P., S. Fritz, A. Barbat, M. Boussaha, M. C. Deloche, C. Grohs, C. Hoze, L. Le Berre, D. Le Bourhis, O. Desnoes, P. Salvetti, L. Schibler, D. Boichard, and A. Capitan. 2017. A missense mutation in PFAS (phosphoribosylformylglycinamidine synthase) is likely causal for embryonic lethality associated with the MH1 haplotype in Montbeliarde dairy cattle. J. Dairy Sci. 100:8176-8187. https:/ /doi.org/10.3168/jds.2017-12579.

R Core Team. 2017. R: A language and environment for statistical computing. R Foundation for Statistical Computing, Vienna, Austria.

Sargolzaei, M., J. P. Chesnais, and F. S. Schenkel. 2014. A new approach for efficient genotype imputation using information from relatives. BMC Genomics 15:478. https://doi.org/10.1186/1471 $-2164-15-478$.

Schütz, E., C. Wehrhahn, M. Wanjek, R. Bortfeld, W. E. Wemheuer, J. Beck, and B. Brenig. 2016. The Holstein Friesian lethal haplotype 5 (HH5) results from a complete deletion of TBF1M and cholesterol deficiency $(\mathrm{CDH})$ from an ERV-(LTR) insertion into the coding region of APOB. PLoS One 11:e0154602. https://doi .org/10.1371/journal.pone.0154602.

VanRaden, P. M., K. M. Olson, D. J. Null, and J. L. Hutchison. 2011. Harmful recessive effects on fertility detected by absence of homozygous haplotypes. J. Dairy Sci. 94:6153-6161. https://doi.org/10 $.3168 /$ jds.2011-4624.

Wang, X., M. Marcinkiewicz, Y. Gatain, M. Bouchard, J. Mao, M. Tremblay, N. Uetani, S. Hanissian, S. Qi, J. Wu, and H. Luo. 2013. Investigation of tissue-specific expression and functions of MLF1-IP during development and in the immune system. PLoS One 8:e63783. https://doi.org/10.1371/journal.pone.0063783.

Zimin, A. V., A. L. Delcher, L. Florea, D. R. Kelley, M. C. Schatz, D. Puiu, F. Hanrahan, G. Pertea, C. P. Van Tassell, T. S. Sonstegard, G. Marcais, M. Roberts, P. Subramanian, J. A. Yorke, and S. L. Salzberg. 2009. A whole-genome assembly of the domestic cow, Bos taurus. Genome Biol. 10:R42. https://doi.org/10.1186/ gb-2009-10-4-r42.

\section{ORCIDS}

M. Mesbah-Uddin () https://orcid.org/0000-0003-1846-0411

D. Boichard (ㄴ) https://orcid.org/0000-0003-0361-2961

A. Capitan (® https://orcid.org/0000-0003-3185-0932 